\title{
Reproducibility and correlation between meat shear force measurements by Warner-Bratzler machine and a Texturometer
}

\author{
Lucas Arantes-Pereira ${ }^{\text {a*}}$, Flávia C. Vargas ${ }^{\mathrm{a}}$, Júlio C. De C. Balieiro ${ }^{\mathrm{a}}$, Ana \\ Monica Q. B. Bittante ${ }^{a}$, and Paulo J. Do A. Sobral ${ }^{a}$ \\ ${ }^{\text {a }}$ Faculty of Animal Science and Food Engineering, University of São Paulo Av. Duque de Caxias Norte, 225 - \\ CEP: 13635-900 - Pirassununga/SP - Brazil \\ ${ }^{*}$ Corresponding author \\ lucas@iftm.edu.br \\ TEL: +55 $343319-6060$ \\ FAX: $+55343319-6001$
}

Received: 22 March 2016; Published online: 18 October 2016

\begin{abstract}
Tenderness has a prominent position on meat quality and is considered to be the sensory characteristic that most influences meat acceptance. Therefore, the aim of this study was to evaluate the accuracy and determine correlations among three different meat shear force techniques. Commercial samples of bovine Longissimus thoracis et lumborum (BLTL), Tensor fasciae latae (BTFL), Semitendinosus (BST), Psoas major (BPM), Biceps femoris (BBF) and swine Longissimus thoracis et lumborum (PLTL) were analyzed for $\mathrm{pH}$, proximate composition, cooking loss and shear force with a classical Warner-Bratzler device and a TA-XT2 Texturometer equipped with shear blades 1 and 3 $\mathrm{mm}$ thick. The effect of different techniques in each studied muscle was statistically analyzed and regression curves were built. Results from the $1 \mathrm{~mm}$ blade were quite similar to the ones obtained with the Warner-Bratzler, however the results from $3 \mathrm{~mm}$ blade were overestimated $(\mathrm{p}<0.05)$. Significant correlation $(\mathrm{p}<0.01)$ among shear force technique using Warner-Bratzler and the ones using the Texturometer was observed ( 0.47 for $1 \mathrm{~mm}$ blade and 0.57 for the $3 \mathrm{~mm}$ blade). In conclusion, we found that the $1 \mathrm{~mm}$ blade and the Warner-Bratzler machine are reproducible for all tested muscles, while the $3 \mathrm{~mm}$ blade is not reproducible for the BTFL, BST, BPM, BBF, PLTL. There is a significant correlation between the results obtained by the classical Warner-Bratzler and the TA-XT2 Texturometer equipped with both blades. Therefore, TA-XT2 Texturometer equipped with the $1 \mathrm{~mm}$ blade can perfectly replace the traditional Warner-Bratzler device.
\end{abstract}

Keywords: Techniques; Tenderness; Variability; Blade thickness

\section{Introduction}

Meat tenderness can be measured by sensory analysis or by instrumental measurements (AMSA, 2015). Instrumental methods have been widely used in meat because this analysis is inexpensive, faster and mainly because it does not requires panelists. Instrumental methods are characterized by reproducibility and repeatabil- ity. Where, repeatability is the variation between measurements that occurs when a person measures the same item several times, using the same measuring equipment, while reproducibility is the variation in the average measurements of different appraisers who measure the same items using the same measuring equipment.

Instrumental methods are widely used to measure meat tenderness. However, special attention 
during the tests is necessary, as meat is a very complex material and its tenderness varies not only among carcasses, but also among muscles and even within the same muscle (Pinto, Ponsano, \& Almeida, 2010; Silva, Contreras-Castillo, \& Marcos Ortega, 2007). Therefore, it is extremely important to reduce the most sources of variation possible during the various steps of the analysis.

Although there are several techniques and apparatus (Hopkins, Lamb, Kerr, \& van de Ven, 2013; de Huidobro, Miguel, Blazquez, \& Onega, 2005; Lorenzen et al., 2010; Xiong, Cavitt, Meullenet, \& Owens, 2006) that perform these tests, results are not necessarily comparable. The most known and used machine for this purpose is the WarnerBratzler (Bourne, 2002), which is the standard machine recommended by the American Meat Science Association (AMSA, 2015). The WarnerBratzler is a mechanical device that uses a steel blade approximately $1 \mathrm{~mm}$ thick and provides data as force value (in kgf), which is the maximum force required to shear a meat sample. This force is then correlated with meat tenderness.

Another widely used device is the Universal Test Machine ("Instron") and recently, the Texturometer, which is a modern and computerized apparatus, used to determine multiple parameters of food texture and other products. The model TA-XT (Stable Micro Systems) with the aid of Warner-Bratzler shear blades has been greatly utilized by meat tenderness researchers (Rosa, Poleti, Balieiro, César, \& Sobral, 2013; Franco \& Lorenzo, 2014; Gama et al., 2013; Lambe et al., 2009; Latorre, Lazaro, Gracia, Nieto, \& Mateos, 2003; Palka, 2003; Ramirez et al., 2004; Vergara \& Gallego, 2000; Yarmand, Nikmaram, Djomeh, \& Homayouni, 2013). Even though, the WarnerBratzler protocol for determining shear force has been standardized with the use of a $1 \mathrm{~mm}$ thick blade, it is common to find TA-XT Texturometers equipped with thicker $3 \mathrm{~mm}$ blades (Pinto et al., 2010). This difference in shear blade thickness may be the cause of inaccuracy in such measurements; nevertheless studies about this subject are still scarce. Although the Texturometer has been widely used, no correlation between the results obtained with the Texturometer and the classical Warner-Bratzler has been yet established.
Considering that tenderness is one of the factors that most influences meat acceptance and that consumers nowadays are even willing to pay more for more tender meat (Font-i-Furnols \& Guerrero, 2014), the establishment of a state of the art and faster technique, that provides more accurate results and low variability to determine meat tenderness is an alternative of great economic importance. Therefore, the aim of this study was to evaluate the accuracy of shear force techniques obtained with the traditional Warner-Bratzler and the TA.XT plus Texturometer equipped with shear blades 1 and $3 \mathrm{~mm}$ thick and also to determine the correlations among them.

\section{Materials and Methods}

\subsection{Sample preparation}

A group of six meat muscles was chosen in order to provide a great range of shear force values, allowing thus the application of this technique to different degrees of tenderness: bovine Longissimus thoracis et lumborum (BLTL), Tensor fasciae latae (BTFL), Semitendinosus (BST), Psoas major (BPM), Biceps femoris (BBF) and swine Longissimus thoracis et lumborum (PLTL). Bovine (Bos indicus) and swine muscles were acquired from local markets and used immediately with no previous treatment. All tests were carried out in triplicate.

Initially, $\mathrm{pH}$ was measured with a digital pHmeter (PG1800, Ind e Com. Eletrônica Gehaka Ltda., São Paulo, Brazil). Each whole muscle was then sliced into three steaks $(2.5 \mathrm{~cm}$ thick), transversally to meat fibers orientation, and placed individually in aluminum trays, and finally cooked in an electric oven (Luxo 2.4 Classic, J. Ryal \& Cia. Ltda., São Paulo, Brazil) at $170{ }^{\circ} \mathrm{C}$. Internal temperature was monitored with a meat probe thermometer (TH1200C, BourdonHaenni, Stuttgart, Germany). Steaks were turned over when internal temperature reached $45^{\circ} \mathrm{C}$, and remained inside the oven until internal temperature attained $70{ }^{\circ} \mathrm{C}$.

After cooking, steaks were allowed to rest and cool to room temperature for approximately four hours. Cores (1.27 cm diameter) were removed in parallel to fiber orientation with the aid of a 
Correlations among different meat shear force techniques $\mid 195$

hand-held coring device. Three cores were taken from each BTFL and BBF steak, 4 cores were taken from PBLTL steaks, 5 cores from BPM and 6 from BLTL and BST steaks, according to each steak's surface area.

\subsection{Shear force determination tests}

A total of 243 cores were used for the shear force determination tests. Cores were equally separated in three different groups and submitted to different shear force techniques. The techniques were performed as follows:

Warner-Bratzler (WB) - One group of samples (cores) was tested with this technique, which was performed with the Warner-Bratzler machine (235 6x, Salter Brecknell, Fairmont MN, USA) equipped with a stainless steel blade of $1.18 \mathrm{~mm}$ of thickness and $126.77 \mathrm{~mm}$ of height containing a vee-shaped $\left(60^{\circ}\right.$ angle) cutting edge (Figure 1a). Crosshead speed was $250 \mathrm{~mm} / \mathrm{min}$ and results were expressed in kgf.

Texturometer (TXT) - The other two core groups were submitted to shear force tests using a Texturometer (TA.XT plus Texture Analyzer, Stable Microsystems Ltd., Surrey, England) and two stainless steel Warner-Bratzler blades of 1.01 mm (TXT1) or $3.07 \mathrm{~mm}$ (TXT3) of thickness with a vee-shaped $\left(60^{\circ}\right.$ angle) cutting edge (Figure $1 \mathrm{~b}$ and $\mathrm{c}$ ). Crosshead speed was $250 \mathrm{~mm} / \mathrm{min}$ and results were expressed also in kgf. In both case, the shear force was determined from the mechanical curves as the maximum force applied, using the Texture Expert V. 4.013.0 software (Stable Microsystems Ltd., Surrey, England).

\subsection{Cooking loss}

To perform the cooking loss assessment, steaks were weighed in aluminum trays previously tared before and after cooking, with an analytical scale (BG2000, Gehaka, Ind e Com. Eletrônica Gehaka Ltda., São Paulo SP, Brazil). Cooking loss percentage was calculated as the difference between both weights, and was expressed as $\%$.

\subsection{Proximate composition}

Meat portions that were not used to assess shear force were mixed and homogenized in a multi blender (Mega master Plus, Philips Walita, São Paulo SP, Brazil) in order to obtain a single and homogeneous sample of each muscle. Consequently, aliquots of those samples were taken to perform moisture, protein, lipid and ash content determinations according to classical methodologies (AOAC, 2011).

\subsection{Statistical analysis}

Three repetitions of each muscle were considered for the statistical analysis, as well as their respective replicates, which varied according to steaks' surface area, as previously mentioned on the item Sample preparation. Descriptive analysis of the shear force data were carried out to characterize each of the assessed apparatus. These analyses were submitted to PROC UNIVARIATE procedure from Statistical Analysis System software (SAS Version 9.2, SAS Institute Inc., Cary, NC). To evaluate shear force, considering the different muscle types and the three techniques, analysis of variance (ANOVA) was used and Tukey's test were carried out as procedures of multiple comparisons whenever significant results were observed.

With the aim of evaluating the existing correlation among techniques, regression analyses of the shear force values obtained with the texturometer (TXT1 and TXT3) as independent variables and of the shear force value obtained with the Warner-Bratzler (WB) as the dependent variable were carried out. Pearson's correlations were also performed to evaluate cooking loss and shear force data.

\section{Results and Discussion}

It is well known that several extrinsic factors (eg.: genotype, age, sex, type of feeding, transport conditions, slaughter, and aging process, for instance), and that some intrinsic factors (eg.: pH, fat, and collagen content) can influence meat tenderness (Koohmaraie, Kent, Shackelford, Veiseth, \& Wheeler, 2002; Stolowski et 


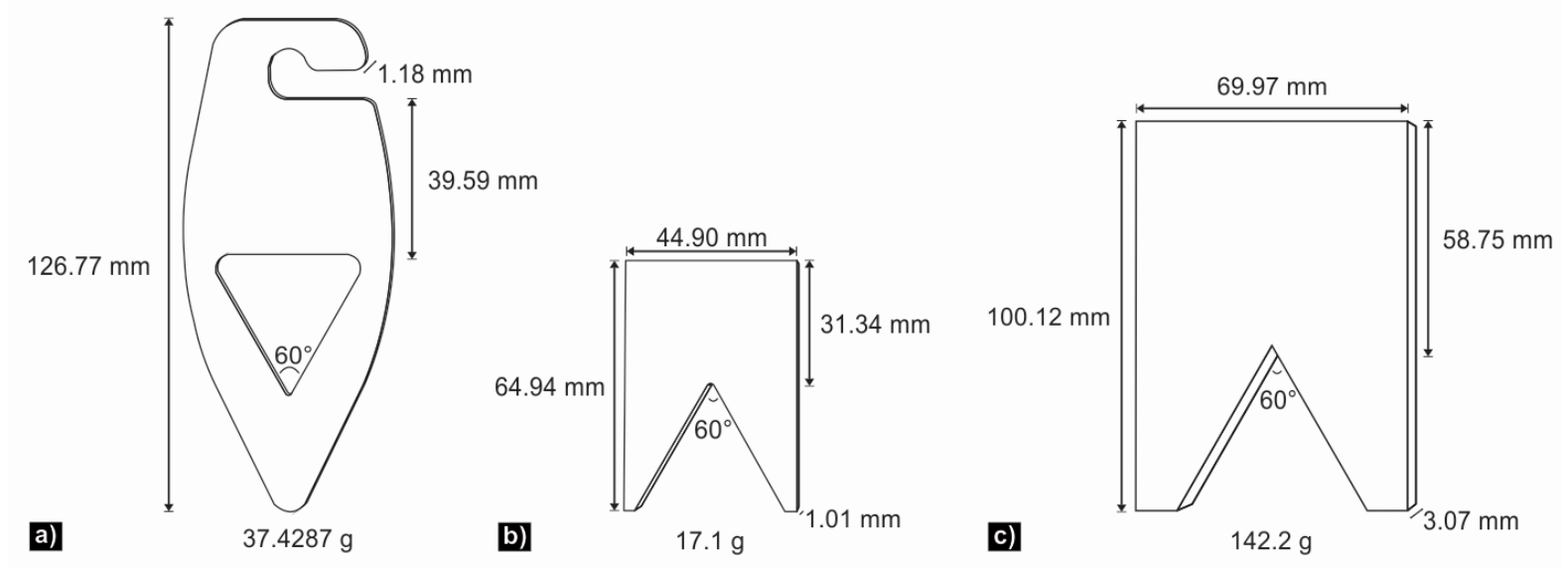

Figure 1: Schemes of the vee-shaped cutting blades: Warner-Bratzler device (a), texturometer $1 \mathrm{~mm}$ thick (b), and $3 \mathrm{~mm}$ thick (c)

al., 2006). However, these intrinsic factors, of basic meat composition, depend on the muscle type, its location, and muscle work intensity during animal's life (Wyrwisz, Poltorak, Zalewska, Zaremba, \& Wierzbicka, 2012). Thus, it is always interesting to know the meat composition (Table 1) when work is carried out on several kinds of muscles.

Beef pH values, between 5.6 and 5.7 (Table 1), can be considered as normal, indicating that suitable pre-slaughter handling was performed. On the other hand, pork $\mathrm{pH}$ (6.2) values were higher $(\mathrm{p}<0.05)$ than beef and above normal range (5.5 to 6.0 ) after $24 \mathrm{~h}$ post mortem (Vanderwal, Bolink, \& Merkus, 1988), suggesting inappropriate pre-slaughter handling.

Moisture ranged from $51.0 \mathrm{~g} 100 \mathrm{~g}^{-1}$ (BBF)

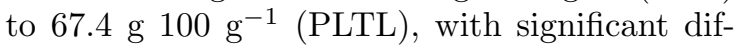
ferences $(\mathrm{p}<0.05)$ among most muscles (Table 1). Protein values varied between $24.7 \mathrm{~g} 100$ $\mathrm{g}^{-1}$ and $33.2 \mathrm{~g} 100 \mathrm{~g}^{-1}$, with BLTL, BPM and PLTL showing the highest values, whereas BTFL and BBF the lowest ones. With regard to lipids, it was observed that BTFL and BBF had the greatest values $(\mathrm{p}<0.05)$, indicating muscles with higher amount of superficial fat and marbling. In contrast, PLTL showed the lowest lipid level $(\mathrm{p}<0.05)$. In general, significant differences were observed among all muscles, except between BTFL and BBF. No significant $(\mathrm{p}>0.05)$ differ- ences among ash content were observed, which

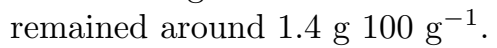

Cooking loss is a functional property inversely related to water holding capacity of meat and is of great technological importance. This parameter is associated with the ability of meat to retain its moisture or juice during the application of external forces, such as cutting, heating, grinding or squeezing. In this study, PLTL had the highest mean value $(37.2 \%)$, which significantly differed $(\mathrm{p}<0.05)$ from BTFL and BST but was not significantly different from BLTL, BPM and BBF. Moreover, BTFL and BST showed the lowest mean values (28.9 and $28.1 \%$, respectively) but were not significantly different from BLTL, $\mathrm{BPM}$ and BBF. Cooking loss is also related to meat tenderness (Yancey, Wharton, \& Apple, 2011), however no strong Pearson's correlation $(0.23,0.16$, and 0.24$)$ among cooking loss (Table 1) and shear force obtained by WB, TXT1, and TXT3, respectively, was observed in the present study.

Besides for BLTL, that showed similar results ( $p>0.05)$, every muscle analyzed presented shear force mean values according to the following descending order: TXT3 $>\mathrm{WB}$ and TXT1 (Table 2), which was expected to some extent, since the amount of force needed to shear the sample increases as the blade thickness is increased (Bourne, 2002). Pinto et al. (2010), evaluating 
Table 1: pH, Proximate composition ( $\left.100 \mathrm{~g}^{-1}\right)$ and Cooking loss (\%) of cooked muscle samples

\begin{tabular}{lcccccc}
\hline \multirow{2}{*}{ Analysis } & \multicolumn{5}{c}{ Muscle $^{1}$} \\
\cline { 2 - 7 } & BLTL & BTFL & BST & BPM & BBF & PLTL \\
\hline $\mathrm{pH}$ & $5.7 \pm 0.1^{a}$ & $5.6 \pm 0.2^{a}$ & $5.6 \pm 0.1^{a}$ & $5.7 \pm 0.1^{a}$ & $5.7 \pm 0.1^{a}$ & $6.2 \pm 0.1^{b}$ \\
Moisture & $57.8 \pm 0.1^{c}$ & $52.2 \pm 0.5^{d}$ & $61.8 \pm 0.1^{b}$ & $58.4 \pm 0.2^{c}$ & $51.0 \pm 0.7^{e}$ & $67.4 \pm 0.1^{a}$ \\
Protein & $28.2 \pm 0.1^{a b}$ & $25.3 \pm 0.8^{c}$ & $27.3 \pm 0.7^{b}$ & $33.2 \pm 1.8^{a}$ & $24.7 \pm 0.6^{c}$ & $28.6 \pm 0.1^{a b}$ \\
Lipid & $9.0 \pm 0.6^{b}$ & $17.9 \pm 0.3^{a}$ & $6.0 \pm 0.3^{c}$ & $3.6 \pm 0.1^{d}$ & $19.1 \pm 0.2^{a}$ & $1.4 \pm 0.1^{e}$ \\
Ash & $1.4 \pm 0.1^{a}$ & $1.4 \pm 0.1^{a}$ & $1.4 \pm 0.1^{a}$ & $1.4 \pm 0.1^{a}$ & $1.4 \pm 0.2^{a}$ & $1.3 \pm 0.1^{a}$ \\
Cooking Loss & $32.2 \pm 1.5^{a b}$ & $28.9 \pm 1.3^{b}$ & $28.1 \pm 0.7^{b}$ & $32.8 \pm 0.9^{a b}$ & $32.7 \pm 1.9^{a b}$ & $37.2 \pm 1.5^{a}$ \\
\hline
\end{tabular}

Data expressed on wet basis; Values represent means \pm observed Standard Error; ${ }^{a-e}$ Means within a row with a common letter do not differ statistically by Tukey's test at a $5 \%$ significance level. ${ }^{1}$ BLTL: Bovine Longissimus thoracis et lumborum, BTFL: Bovine Tensor fasciae latae, BST: Bovine Semitendinosus, BPM: Bovine Psoas major, BBF: Bovine Biceps femoris; PLTL: Swine Longissimus thoracis et lumborum

the effect of blade thickness using a texturometer on texture of Longissimus, observed that the $1 \mathrm{~mm}$ blade provides greater sensibility to the assay when compared to the $3 \mathrm{~mm}$ one.

The lowest mean values were obtained for BLTL within each tested technique. Besides that, mean values of WB and TXT1 were very similar, suggesting a good similarity between these techniques for that muscle. Similar behavior was also observed for BST. The muscles BBF and BPM showed the highest mean shear force values for all the tested techniques. BBF results were in agreement to what has been found in the literature (Hildrum et al., 2009; Shackelford, Wheeler, \& Koohmaraie, 1995; Stolowski et al., 2006); however, BPM results were in disagreement (Belew, Brooks, McKenna, \& Savell, 2003; Rhee, Wheeler, Shackelford, \& Koohmaraie, 2004; Shackelford et al., 1995). This fact may indicate the occurrence of other physical principles than shearing during the tests, since this muscle is reported as one of the most tender in several studies about sensory texture (Carmack, Kastner, Dikeman, Schwenke, \& Zepeda, 1995; Rhee et al., 2004; Shackelford et al., 1995). PLTL presented relatively low means compared to bovine muscles. WB and TXT1 results for this muscle were similar to what has been reported by Rees, Trout, and Warner (2002) in different locations along swine Longissimus thoracis et lumborum muscles.

For all applied techniques, BLTL and BST showed very similar data variation (standard error) within each muscle. With such results, effect of the techniques used to determine shear force is evidently a minor issue for these muscles. On the contrary, BBF and BPM showed the greatest variation when compared to the other bovine muscles, which is probably related to the highest mean values and the possible occurrence of other physical principles besides shearing. BTFL presented the lowest data variation (standard error values), while PLTL showed the greatest. Besides the possible occurrence of other physical principles, these values may also indicate an effect of the intrinsic factors from the meat muscle (PLTL) on the test performance and accuracy. Shackelford et al. (1995), in a study about shear force of 10 different muscles reported standard error values of $0.3,0.2,0.1$, and 0.2 for BLTL, BST, BPM, and BBF, respectively. Contradictorily, Belew et al. (2003) found very low standard errors (0.05) for BPM, BTFL, Bovine Longissimus thoracis, and Bovine Longissimus lumborum. Such differences may occur because according to Koohmaraie et al. (2002) intrinsic factors affecting meat tenderness are muscle dependent. Besides that, it is well known that different animal breed or category can also influence meat tenderness.

The texturometer equipped with the $3 \mathrm{~mm}$ blade presented less accuracy (standard errors) and higher mean values for most muscles, suggesting that this blade overestimated results and promoted greater variability in determining meat tenderness by shear force. On the contrary, TXT1 showed more accuracy for most muscles. After the analysis of variance (Table 2), it was 
198 | Arantes-Pereira et al.

Table 2: Summary of analysis of variance and unfolding of the effect of different techniques on each studied muscle

\begin{tabular}{|c|c|c|c|c|}
\hline Variation sources & \multicolumn{2}{|c|}{ Degrees of freedom } & \multicolumn{2}{|c|}{$\operatorname{Pr}>\mathbf{F}$} \\
\hline Muscle & \multicolumn{2}{|l|}{5} & \multicolumn{2}{|c|}{$<0.0001^{* *}$} \\
\hline Technique & \multicolumn{2}{|l|}{2} & \multicolumn{2}{|c|}{$<0.0001^{* *}$} \\
\hline Muscle x Technique & \multicolumn{2}{|l|}{10} & \multicolumn{2}{|c|}{$0.0330^{*}$} \\
\hline \multicolumn{2}{|c|}{ Muscle } & $\begin{array}{c}W B \\
(\mathrm{kgf})\end{array}$ & $\begin{array}{r}\text { TXT1 } \\
\text { (kgf) }\end{array}$ & $\begin{array}{c}\text { TXT3 } \\
\text { (kgf) }\end{array}$ \\
\hline \multicolumn{2}{|c|}{ Longissimus thoracis et lumborum (BLTL) } & $5.2 \pm 0.3^{a}$ & $4.6 \pm 0.3^{a}$ & $6.1 \pm 0.3^{a}$ \\
\hline \multicolumn{2}{|c|}{ Tensor fasciae latae (BTFL) } & $6.2 \pm 0.5^{b}$ & $4.6 \pm 0.1^{b}$ & $9.6 \pm 0.8^{a}$ \\
\hline \multicolumn{2}{|c|}{ Semitendinosus (BST) } & $6.6 \pm 0.2^{b}$ & $6.4 \pm 0.3^{b}$ & $8.5 \pm 0.2^{a}$ \\
\hline \multicolumn{2}{|l|}{ Psoas Major (BPM) } & $8.1 \pm 0.5^{b}$ & $7.4 \pm 0.4^{b}$ & $12.2 \pm 0.8^{a}$ \\
\hline \multicolumn{2}{|l|}{ Biceps femoris $(\mathrm{BBF})$} & $9.5 \pm 0.7^{b}$ & $8.0 \pm 0.8^{b}$ & $12.2 \pm 1.2^{a}$ \\
\hline \multicolumn{2}{|c|}{ Swine Longissimus thoracis et lumborum (PLTL) } & $6.3 \pm 0.7^{b}$ & $5.4 \pm 0.6^{b}$ & $8.4 \pm 1.2^{a}$ \\
\hline
\end{tabular}

* $(\mathrm{p}<0.01) ; * *(\mathrm{p}<0.05)$; Values represent means \pm observed Standard Error; ${ }^{a-b}$ Means in a row followed by a common letter do not differ statistically by Tukey's test at a $5 \%$ significance level. WB = Warner-Bratzler; TXT1 = Texturometer $1 \mathrm{~mm}$; TXT3 = Texturometer 3 mm

Table 3: Equations obtained by regression analyses among shear force results obtained by WarnerBratzler and Texturometer with 1 and $3 \mathrm{~mm}$ thick shear blades

\begin{tabular}{cccc}
\hline $\mathbf{N}^{1}$ & Equation & $\mathbf{R}^{2}$ & $\mathbf{P r}>\mathbf{F}$ \\
\hline 81 & $\mathrm{Y}_{W B}=1.96+0.80 \mathrm{X}_{T X T 1}$ & 0.47 & $<0.0001^{* *}$ \\
81 & $\mathrm{Y}_{W B}=2.29+0.49 \mathrm{X}_{T X T 3}$ & 0.57 & $<0.0001^{* *}$ \\
\hline
\end{tabular}

** $(\mathrm{p}<0.05) ;{ }^{1}$ Number of samples. $\mathrm{Y}_{W B}=$ Shear force by Warner-Bratzler $(\mathrm{kgf}) ; \mathrm{X}_{T X T 1}=$ Shear force by Texturometer $1 \mathrm{~mm}(\mathrm{kgf})$; $\mathrm{X}_{T X T 3}=$ Shear force by Texturometer $3 \mathrm{~mm}(\mathrm{kgf})$

observed that the interaction muscle $\mathrm{x}$ technique was significant at a $5 \%$ probability, indicating the dependence between them.

Among the six target muscles, only BLTL was not significantly influenced ( $\mathrm{p}>0.05)$ by the technique. For all the other muscles, shear force results obtained by the TXT3 were significantly higher $(\mathrm{p}<0.05)$ than results obtained by WB and TXT1, confirming that this technique overestimated the shear force results for such muscles. This behavior must be credited to the meat tissue structure, structure variability and to the fact that the blade pressure (force/area) is smaller for a larger area blade. In this situation the total force needed to shear the meat sample will probably be influenced by a larger compression component, as well as by a larger portion of the convective tissue, which has to be ruptured. Similarly, Pinto et al. (2010) did not find significant difference $(\mathrm{p}>0.05)$ between re- sults obtained for Bovine Longissimus dorsi using 1 and $3 \mathrm{~mm}$ blades. In this same study, comparing shear force of samples submitted to slow and fast chilling, authors reported significant difference when using $1 \mathrm{~mm}$ shear blade, whereas no difference among samples was obtained with the $3 \mathrm{~mm}$ one.

With the aim of evaluating the existing correlations among techniques, regression analyses (Table 2) using shear force results were performed. Linear equations with coefficients of determination $\left(\mathrm{R}^{2}\right) 0.47$ and 0.57 between shear force results obtained by WB and TXT1 and WB and TXT3 (Figure 2), respectively, were obtained. Although coefficients of determination were relatively low, models were significant (Table 3) and able to predict shear force value of one technique based on the other.

If a meat shear force apparatus provided identical or proportional results to the ones obtained 


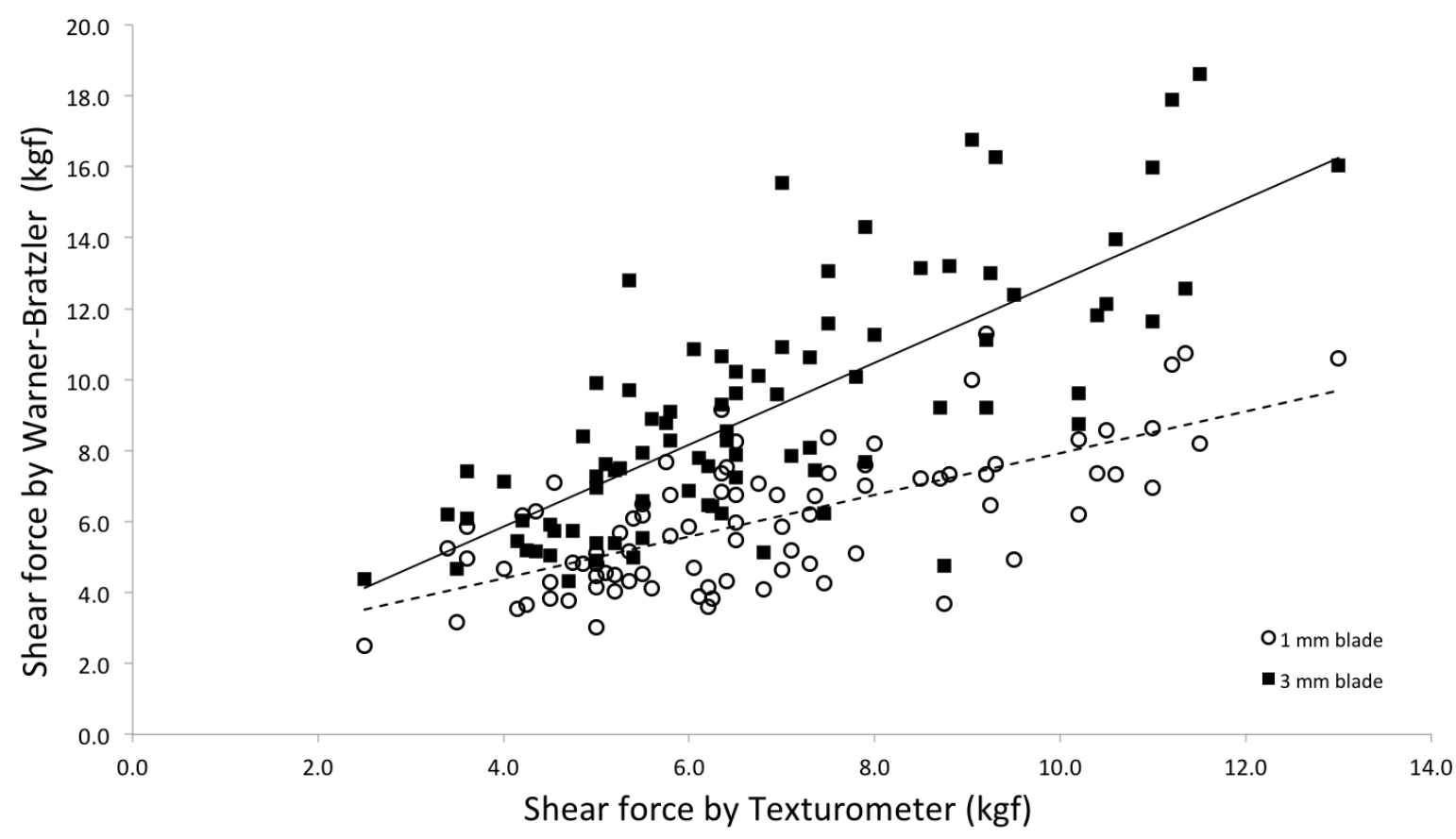

Figure 2: Correlation of shear force results obtained by Warner-Bratzler and Texturometer with a $1 \mathrm{~mm}$ shear blade (dashed line and open circles) and by Warner-Bratzler and Texturometer with a 3 mm shear blade (solid line and filled squares)

by the Warner-Bratzler device, linear correlations with angular coefficients equal to one (the unit) would be expected. Nevertheless, in this study it was observed that the angular coefficients not only differed from the unit, but also differed among themselves: TXT1 coefficient was close to one, whereas the one obtained for TXT3 was not (Table 3). The main consequence of such differences is that values calculated with the equations generated will be more or less distant from the expected, according to their magnitude. The first possible explanation for this difference between the angular coefficients would be the difference in thickness of blades, since by definition tension is the quotient of applied force by the area in which the force was applied (Bourne, 2002). Nonetheless, it was observed that the ratio between the thickness of the blades used at the texturometer, which was $3.04(3.07 \mathrm{~mm} / 1.01$ $\mathrm{mm}$ ), is superior to the ratio between the respective angular coefficients of $0.61(0.49 / 0.8)$. Thus, other possible explanations for these find- ings may be related to: i) differences in obtaining cores (Otremba et al., 1999; Wheeler et al., 1996; Wheeler, Shackelford, \& Koohmaraie, 1997); ii) differences between the cooking endpoint of samples (Obuz, Dikeman, Grobbel, Stephens, \& Loughin, 2004; Wheeler et al., 1996; Yancey et al., 2011), despite the rigorous control of the process; iii) differences in the speeds of the shear blades, which is difficult to predict, since this parameter is fixed, but not necessarily known, at the Warner-Bratzler device (Wheeler et al., 1997); iv) and due to a slight difference in the shapes of blades, since the one used at the Warner-Bratzler device (Figure 1a) has a round shaped angle (Otremba et al., 1999), while texturometer ones have triangular shape with a welldefined angle (Figure 1b,c).

Lorenzen et al. (2010) found correlation coefficients ranging from 0.49 to $0.69(\mathrm{p}<0.05)$ when comparing Warner-Bratzler and Slice Shear Force techniques on commercial samples of top loin in the USA, which were lower than the re- 
sults found in the current work (0.69 and 0.75).

\section{Conclusions}

The $1 \mathrm{~mm}$ blade (TA.XT plus Texture Analyzer, V shaped blade) and the Warner-Bratzler (Warner-Bratzler machine) are reproducible for all tested muscles as well as the $3 \mathrm{~mm}$ blade solely for the BLTL muscle. Consequently these techniques will statistically generate similar results for the reported muscles. However the $3 \mathrm{~mm}$ blade is not reproducible compared to the $1 \mathrm{~mm}$ blade and the Warner-Bratzler for the BTFL, BST, BPM, BBF, PLTL.

With experimental conditions prevailing in this study, there is a significant correlation between the results of shear force determination obtained by the technique using the classical Warner-Bratzler and the TA-XT2 Texturometer equipped with shear blades 1 and $3 \mathrm{~mm}$ thick.

The TXT1 technique is an accurate method for evaluating meat tenderness in different beef muscles. The TA-XT2 Texturometer, which is as modern apparatus, equipped with the $1 \mathrm{~mm}$ shear blade can perfectly replace the traditional Warner-Bratzler device, since these techniques are strongly correlated and results from both techniques are statistically the same.

\section{References}

AMSA. (2015). Research guidelines for cookery, sensory evaluation and instrumental tenderness measurements of fresh meat (2nd ed.) Champaign, Illinois: American Meat Science Association.

AOAC. (2011). Official methods of analysis of the association of official analytical chemists international. W. Horwitz \& G. W. Latimer, Eds. Recovery studies, 17th edn. Byrd Richmond, VA (18th ed.). Gaithersburg, MD: Pharmabooks.

Belew, J. B., Brooks, J. C., McKenna, D. R., \& Savell, J. W. (2003). Warner-Bratzler shear evaluations of 40 bovine muscles. Meat Science, 64 (4), 507-512. doi:10.1016/S03091740(02)00242-5

Bourne, M. (2002). Food texture and viscosity: concept and measurement. Academic press.
Carmack, C. F., Kastner, C. I., Dikeman, M. E., Schwenke, J. R., \& Zepeda, C. M. G. (1995). Sensory evaluation of beef-flavor intensity, tenderness, and juiciness among major muscles. Meat Science, 39(1), 143147. doi:10.1016/0309-1740(95)80016-6

de Huidobro, F. R., Miguel, E., Blazquez, B., \& Onega, E. (2005). A comparison between two methods (Warner-Bratzler and texture profile analysis) for testing either raw meat or cooked meat. Meat Science, 69(3), 527536. doi:10.1016/j.meatsci.2004.09.008

Font-i-Furnols, M. \& Guerrero, L. (2014). Consumer preference, behavior and perception about meat and meat products: An overview. Meat Science, 98(3, SI), 361371. 60th International Congress of Meat Science and Technology (ICoMST), Punta del Este, URUGUAY, AUG 17-22, 2014. doi:10.1016/j.meatsci.2014.06.025

Franco, D. \& Lorenzo, J. M. (2014). Effect of muscle and intensity of finishing diet on meat quality of foals slaughtered at 15 months. Meat Science, 96(1), 327-334. doi:10.1016/j.meatsci.2013.07.018

Gama, L. T., Bressan, M. C., Rodrigues, E. C., Rossato, L. V., Moreira, O. C., Alves, S. P., \& Bessa, R. J. B. (2013). Heterosis for meat quality and fatty acid profiles in crosses among Bos indicus and Bos taurus finished on pasture or grain. Meat Science, 93(1), 98-104. doi:10.1016/j.meatsci.2012.08.005

Hildrum, K. I., Rodbotten, R., Hoy, M., Berg, J., Narum, B., \& Wold, J. P. (2009). Classification of different bovine muscles according to sensory characteristics and Warner Bratzler shear force. Meat Science, 83(2), 302-307. doi:10.1016/j.meatsci.2009.05.016

Hopkins, D. L., Lamb, T. A., Kerr, M. J., \& van de Ven, R. J. (2013). The interrelationship between sensory tenderness and shear force measured by the G2 Tenderometer and a Lloyd texture analyser fitted with a Warner-Bratzler head. Meat Science, 93(4), 838-842. doi:10 . 1016 / j . meatsci.2012.11.052

Koohmaraie, M., Kent, M. P., Shackelford, S. D., Veiseth, E., \& Wheeler, T. L. (2002). Meat tenderness and muscle growth: is there any relationship? Meat Science, 62(3, SI), 345- 
Correlations among different meat shear force techniques $\mid 201$

352. 48th International Congress of Meat Science and Technology, ROME, ITALY, AUG 25-30, 2002. doi:10 . 1016 / S0309 1740(02)00127-4

Lambe, N. R., Navajas, E. A., Buenger, L., Fisher, A. V., Roehe, R., \& Simm, G. (2009). Prediction of lamb carcass composition and meat quality using combinations of post-mortem measurements. Meat Science, 81(4), 711-719. doi:10.1016/j . meatsci.2008.10.025

Latorre, M. A., Lazaro, R., Gracia, M. I., Nieto, M., \& Mateos, G. G. (2003). Effect of sex and terminal sire genotype on performance, carcass characteristics, and meat quality of pigs slaughtered at $117 \mathrm{~kg}$ body weight. Meat Science, 65(4), 1369-1377. doi:10.1016/S0309-1740(03)00059-7

Lorenzen, C. L., Calkins, C. R., Green, M. D., Miller, R. K., Morgan, J. B., \& Wasser, B. E. (2010). Efficacy of performing Warner-Bratzler and slice shear force on the same beef steak following rapid cooking. Meat Science, 85(4), 792-794. doi:10. 1016/j.meatsci.2010.03.030

Obuz, E., Dikeman, M. E., Grobbel, J. P., Stephens, J. W., \& Loughin, T. M. (2004). Beef longissimus lumborum, biceps femoris, and deep pectoralis WarnerBratzler shear force is affected differently by endpoint temperature, cooking method, and USDA quality grade. Meat Science, 68(2), 243-248. doi:10.1016/j . meatsci . 2004.03 .003

Otremba, M. M., Dikeman, M. E., Milliken, G. A., Stroda, S. L., Unruh, J. A., \& Chambers, E. (1999). Interrelationships among evaluations of beef longissimus and semitendinosus muscle tenderness by WarnerBratzler shear force, a descriptive-texture profile sensory panel, and a descriptive attribute sensory panel. Journal of Animal Science, 7ry(4), 865-873.

Palka, K. (2003). The influence of post-mortem ageing and roasting on the microstructure, texture and collagen solubility of bovine semitendinosus muscle. Meat Science, 64 (2), 191-198. doi:10.1016/S03091740(02)00179-1
Pinto, M. F., Ponsano, E. H. G., \& Almeida, A. P. d. S. (2010). Shear blade thickness in the instrumental evaluation of meat texture. Ciência Rural, 40(6), 1405-1410.

Ramirez, J. A., Oliver, M. A., Pla, M., Guerrero, L., Arino, B., Blasco, A., ... Gil, M. (2004). Effect of selection for growth rate on biochemical, quality and texture characteristics of meat from rabbits. Meat Science, 67(4), 617-624. doi:10.1016/j . meatsci . 2003.12.012

Rees, M. P., Trout, G. R., \& Warner, R. D. (2002). Tenderness, ageing rate and meat quality of pork M-longissimus thoracis et lumborum after accelerated boning. Meat Science, 60(2), 113-124. doi:10 . 1016/ S0309-1740(01)00085-7

Rhee, M. S., Wheeler, T. L., Shackelford, S. D., \& Koohmaraie, M. (2004). Variation in palatability and biochemical traits within and among eleven beef muscles. Journal of Animal Science, 82(2), 534-550.

Rosa, A. F., Poleti, M. D., Balieiro, J. C. C., César, M. C., \& Sobral, P. J. A. (2013). Effect of the modified atmosphere effect of the modified atmosphere and masterpack packaging on pork meat characteristics during refrigerated storage. International Journal of Food Studies, (2), 167-179. doi:10.7455/ ijfs/2.2.2013.a4

Shackelford, S. D., Wheeler, T. L., \& Koohmaraie, M. (1995). Relationship between shear force and trained sensory panel tenderness ratings of 10 major muscles from Bos-indicus and Bos-taurus cattle. Journal of Animal Science, 73(11), 3333-3340.

Silva, M. d. L., Contreras-Castillo, C. J., \& Marcos Ortega, E. M. (2007). Effect of cooking on the quality of beef Semitendinosus muscle. Ciencia e Tecnologia de Alimentos, 27(3), 441-445.

Stolowski, G. D., Baird, B. E., Miller, R. K., Savell, J. W., Sams, A. R., Taylor, J. F., ... Smith, S. B. (2006). Factors influencing the variation in tenderness of seven major beef muscles from three Angus and Brahman breed crosses. Meat Science, 73(3), 475483. doi:10.1016/j.meatsci.2006.01.006 
Vanderwal, P. G., Bolink, A. H., \& Merkus, G. S. M. (1988). Differences in quality characteristics of normal, PSE and DFD pork. Meat Science, 24(1), 79-84. doi:10.1016/ 0309-1740(89)90009-0

Vergara, H. \& Gallego, L. (2000). Effect of electrical stunning on meat quality of lamb. Meat Science, 56(4), 345-349. doi:10.1016/ S0309-1740(00)00061-9

Wheeler, T. L., Shackelford, S. D., Johnson, I. P., Miller, M. F., Miller, R. K., \& Koohmaraie, M. (1996). A comparison of Warner-Bratzler shear force assessment within and among institutions. Journal of Animal Science, 75(9), 2423-2432. doi:10. 2527/1996.7471553x

Wheeler, T. L., Shackelford, S. D., Johnson, L. P., Miller, M. F., Miller, R. K., \& Koohmaraie, M. (1997). A comparison of warner-bratzler shear force assessment within and among institutions. Journal of Animal Science, 75(9), 2423-2432.

Wheeler, T. L., Shackelford, S. D., \& Koohmaraie, M. (1997). Standardizing collection and interpretation of warnerbratzler shear force and sensory tenderness data. In Proc. recip. meat conf (Vol. 50, pp. 68-77). Citeseer.

Wyrwisz, J., Poltorak, A., Zalewska, M., Zaremba, R., \& Wierzbicka, A. (2012). Analysis of relationship between basic composition, $\mathrm{PH}$, and physical properties of selected bovine muscles. Bulletin of the Veterinary Institute in Pulawy, 56(3), 403409.

Xiong, R., Cavitt, L. C., Meullenet, J. F., \& Owens, C. M. (2006). Comparison of allokramer, warner-bratzler and razor blade shears for predicting sensory tenderness of broiler breast meat. Journal of Texture Studies, 37(2), 179-199.

Yancey, J. W. S., Wharton, M. D., \& Apple, J. K. (2011). Cookery method and endpoint temperature can affect the WarnerBratzler shear force, cooking loss, and internal cooked color of beef longissimus steaks. Meat Science, 88(1), 1-7. doi:10 . 1016/j.meatsci.2010.11.020

Yarmand, M. S., Nikmaram, P., Djomeh, Z. E., \& Homayouni, A. (2013). Microstructural and mechanical properties of camel longissimus dorsi muscle during roasting, braising and microwave heating. Meat Science, 95(2), 419-424. doi:10.1016/j . meatsci . 2013.05.018

$$
\text { IJFS | October 2016 | Volume } 5 \text { | pages 193-202 }
$$

